\title{
National survey of healthcare providers' views on the risk of inadvertent exposure of pregnant patients to ionizing radiation in Canadian radiotherapy departments
}

\author{
Robert A. Olson • Julianna Caon • Scott Tyldesley • \\ Alanah Bergman • Ming Fong • Vivian Ma • \\ Rosemin Vellani • Mohamed Khan • Karen Goddard
}

Received: 21 November 2011 / Accepted: 12 December 2011 /Published online: 1 February 2012

(C) Springer-Verlag 2012

\begin{abstract}
Background Women of child-bearing age are at risk of developing a malignancy that may require treatment with radiation therapy (RT). Radiation exposure to pregnant patients is associated with a risk of fetal malformation and death.

Methods An online survey was created and distributed to all radiation oncologists (RO), radiation oncology residents (ROR), radiation therapists (RTT), and medical physicists who were members of their respective national professional organizations $(n=2,146)$.

Results Of the respondents, 317 (15\%) completed the questionnaire. Only $58 \%$ of ROs/RORs remembered to discuss
\end{abstract}

R. A. Olson · J. Caon $\cdot$ S. Tyldesley $\cdot$ M. Khan $\cdot$ K. Goddard $(\bowtie)$ Department of Radiation Oncology, Vancouver Centre,

BC Cancer Agency,

600 West 10th Ave,

Vancouver, BC V5Z 4E6, Canada

e-mail: kgoddard@bccancer.bc.ca

R. A. Olson · J. Caon $\cdot$ S. Tyldesley $\cdot$ V. Ma $\cdot$ M. Khan $•$

K. Goddard

University of British Columbia,

Vancouver, BC, Canada

R. A. Olson

Department of Radiation Oncology, Centre for the North,

BC Cancer Agency,

Vancouver, BC, Canada

A. Bergman

Department of Medical Physics, Vancouver Centre,

BC Cancer Agency,

Vancouver, BC, Canada

M. Fong $\cdot$ R. Vellani

Department of Radiation Therapy, Vancouver Centre,

BC Cancer Agency,

Vancouver, BC, Canada the risk of RT in pregnancy most of the time. The majority (70\%) of respondents did not believe or know if RTTs discussed the risks of radiation in pregnancy. In addition, $65 \%$ either thought no warning signs existed in their department or were unsure of their existence. Furthermore, only $8 \%$ of respondents believed their center had handouts for patients. Of the respondents, $9 \%$ encountered a situation where a pregnant patient was inadvertently treated with RT, while $13 \%$ encountered a situation where a pregnant patient was almost inadvertently treated with RT. There was no significant difference by province in the proportion of respondents who reported inadvertent or almost inadvertent RT in pregnancy (range, $6-24 \%$; $p=0.20$ ).

Conclusion Nationally, respondents believe there are inadequate mechanisms to prevent inadvertent ionizing radiation exposure to pregnant patients and one fifth of respondents encountered situations in which a pregnant patient was, or was almost inadvertently irradiated. This suggests that national guidelines and detailed institutional policies and procedures are needed.

Keywords Cancer Pregnancy - Radiation therapy · Radiation safety $\cdot$ Risk reduction

\section{Introduction}

Women of child-bearing age are at risk of developing a malignancy that requires treatment with radiation therapy (RT), in particular breast cancer, cervical cancer, leukemia, lymphoma, and melanoma [1-5]. Radiation exposure to a developing fetus can result in growth retardation, malformations, future malignancy, and even spontaneous abortion depending on the dose received and stage of pregnancy [1, 
Table 1 Survey questions

What is your occupation?

Which Canadian province do you work in?

How many years have you worked in this field?

Are you male or female?

How many linear accelerators are there at your center?

As far as you know, as part of the radiation therapist's education session with potentially fertile patients, is it mandatory to discuss the risk of RT during pregnancy?

If you are a radiation oncologist or radiation oncology resident, how often do you remember to discuss the risk of RT in pregnancy during the initial consultation with a potentially fertile female patient? ${ }^{\mathrm{a}}$

If you are a radiation oncologist or radiation oncology resident, when you meet with the patient prior to RT planning, how often do you remember to discuss the risk of RT in pregnancy with a potentially fertile female patient? ${ }^{\mathrm{a}}$

Are warning signs/notices asking patients to notify staff if they think they might be pregnant in use at your cancer center? ${ }^{\mathrm{a}}$

Do you have any patient education materials or handouts at your cancer center specifically about the risks associated with RT in early pregnancy? ${ }^{\mathrm{a}}$ Is it mandatory for potentially fertile female patients to have a pregnancy test prior to RT planning or treatment at your cancer center? ${ }^{\mathrm{a}}$

Do you think it would be appropriate for potentially fertile female patients to have a pregnancy test prior to RT planning or treatment? ${ }^{\mathrm{a}}$ lumpectomy for early stage breast cancer. Only after her RT is completed, is it The radiation therapist who administered the radiotherapy discovered that she had been in the first trimester of pregnancy during her RT. She did not remember being told by her physician, or HCPs, that RT in these circumstances could be hazardous. There were no signs in the department Both the oncologists and the radiation therapist

The cancer institute where she was treated warning her that she should notify her HCPs if she thought that she was pregnant. She was never given any relevant patient education materials. Who is responsible for this error? ${ }^{\mathrm{a}}$

In this same case, in your opinion which party would be most likely to be found liable in a court of law? ${ }^{\mathrm{a}}$

The patient's radiation oncologist

The radiation therapist who administered the radiotherapy

Both the oncologists and the radiation therapist

The cancer institute where she was treated

Does the radiation oncologist owe a "duty of care" to the patient's unborn child?

How many times have you encountered a situation where a pregnant patient was What anonymous details can you remember about the almost treated accidentally with RT, but the pregnancy was detected in time to prevent this from happening?

Did this/these event(s) occur in Canada? ${ }^{\mathrm{a}}$

How many times have you encountered a situation where a pregnant patient was actually given RT accidentally?

circumstances and how long ago did this/these event(s) occur?

Did this/these event(s) occur in Canada? ${ }^{a}$

How effective do you think the following methods are to help prevent accidental Prominent display of warning signs/notices to catch the attention treatment of a pregnant cancer patient with RT?

What anonymous details can you remember about the circumstances and how long ago did this/these event(s) occur?
Discussion during therapist/patient education session

Discussion with treating oncologist

Handouts/patient education materials

Mandatory pregnancy test for any potentially fertile patient prior to RT planning or treatment

Would it be helpful to have a checklist (listing the different steps taken to warn the patient about risks of RT and pregnancy and to ensure that the patient is not pregnant) to complete for potentially fertile female patients prior to any RT? ${ }^{\mathrm{a}}$

Do you think that it would be helpful to have a set of National Canadian Guidelines in place to help prevent accidental treatment of pregnant patients with RT?

${ }^{\mathrm{a}}$ Comments were elicited

2, 6-11]. If patients and healthcare providers (HCPs) are aware of a potential pregnancy, techniques can often be used to limit the RT dose to the fetus, or avoid RT altogether [6, 12]. It is therefore imperative that patients are aware of the risk, and mechanisms are in place to prevent inadvertent RT to pregnant patients.
A survey of RT HCPs in British Columbia (BC), suggested that inadequate mechanisms were in place to prevent inadvertent irradiation of pregnant patients [13]. The primary objective of this study was to assess whether other departments across Canada had similar concerns. Secondarily, this study sought to assess HCPs opinions on which potential 
Table 2 Radiation oncologist respondents' discussion at consult or radiotherapy planning

\begin{tabular}{llc}
\hline & \multicolumn{2}{l}{$\begin{array}{l}\text { How often oncologist discusses risk of radiation } \\
\text { during pregnancy at: }\end{array}$} \\
\cline { 2 - 3 } & Consult (\%) & $\begin{array}{l}\text { Radiotherapy } \\
\text { planning (\%) }\end{array}$ \\
\hline Never & 4 & 9 \\
Almost never & 12 & 21 \\
Occasionally & 26 & 25 \\
Almost always & 42 & 32 \\
Always & 16 & 13 \\
\hline
\end{tabular}

mechanisms to prevent inadvertent RT to pregnant patients would be most effective.

\section{Methods}

This study was approved by the University of British Columbia Research Ethics Board. An online survey that was created and distributed using Survey Monkey ${ }^{\circledR}$, an online anonymous survey tool (LCC Copyright 2010), to 2,146 HCPs working in radiotherapy departments nationally. The questions asked are presented in Table 1. HCPs were invited by email to participate. This request was made to all radiation therapists, medical physicists, radiation oncologists, and radiation oncology residents who were members of their respective national organizations. Participation was voluntary, anonymous, and not compensated. The survey contained 19 multiple-choice questions with optional open-ended comment sections and is described elsewhere in the provincial pilot study [13].

Statistical analyses

Respondents' opinions were presented with descriptive statistics. Chi-square tests were used to assess differences in views on effectiveness of each potential intervention by occupation of respondent and differences in proportions of respondents who have experience with inadvertent RT by province of residence. All tests were two-sided and significance was defined by $p<0.05$. All analyses were conducted
Table 4 Proportion of respondents who encountered a situation where a pregnant patient was or was almost inadvertently given radiotherapy

\begin{tabular}{lcc}
\hline Frequency & $\begin{array}{l}\text { Inadvertent } \\
\text { radiotherapy given (\%) }\end{array}$ & $\begin{array}{l}\text { Inadvertent radiotherapy } \\
\text { almost given (\%) }\end{array}$ \\
\hline Never & 91 & 87 \\
Once & 7 & 8 \\
Twice & 1 & 4 \\
Three or & 1 & 1 \\
more times & & \\
\hline
\end{tabular}

using Statistical Package for Social Sciences, version 17.0 (SPSS, Chicago, IL, USA).

\section{Results}

Of the respondents, 317 (15\%) completed the questionnaire presented in Table 1 with the highest response rate from radiation oncologists (ROs; 34\%). The majority of respondents were radiation therapists $(55 \%)$, followed by ROs (31\%), medical physicists (10\%), and RORs (4\%). The mean years in practice was 11 (range, 0-37). All Canadian provinces, with the exception of Nova Scotia, were represented.

Table 2 displays how often radiation oncologists perceive they discuss the risk of RT in pregnancy. Table 3 displays respondents' views on other potential interventions that were employed at their institution at the time of the survey. Table 4 presents the proportion of respondents who have encountered a situation where a pregnant patient was inadvertently or almost treated with RT. Of the respondents, 19\% reported at least one incidence where a pregnant patient was or almost was inadvertently treated with RT. There was no significant difference by province in proportion of respondents who encountered a situation where a pregnant patient received or almost received inadvertent RT (range, 6-24\%; $p=0.20)$.

Figure 1 displays respondents' views on their perceived effectiveness of potential interventions to reduce the risk of inadvertent RT in pregnancy, divided by respondents' occupation. Of the respondents, $84 \%$ believed that a set of National Canadian Guidelines would be helpful to prevent
Table 3 Respondents' opinions on potential interventions already in place

\begin{tabular}{lccc}
\hline & \multicolumn{2}{l}{ Percentage who have intervention in place } \\
\cline { 2 - 4 } & Yes (\%) & No (\%) & Do not know (\%) \\
\hline Discussion of risk by radiation therapist & 30 & 45 & 25 \\
Patient education materials or handouts & 8 & 37 & 55 \\
Warning signs asking patients notify staff if pregnant & 35 & 47 & 18 \\
Mandatory pregnancy tests for potentially fertile patients & 6 & 57 & 37 \\
\hline
\end{tabular}


Fig. 1 Proportion of respondents', divided by occupation, who indicated potential interventions to prevent inadvertent radiotherapy to pregnant patients are "somewhat effective" or "very effective"

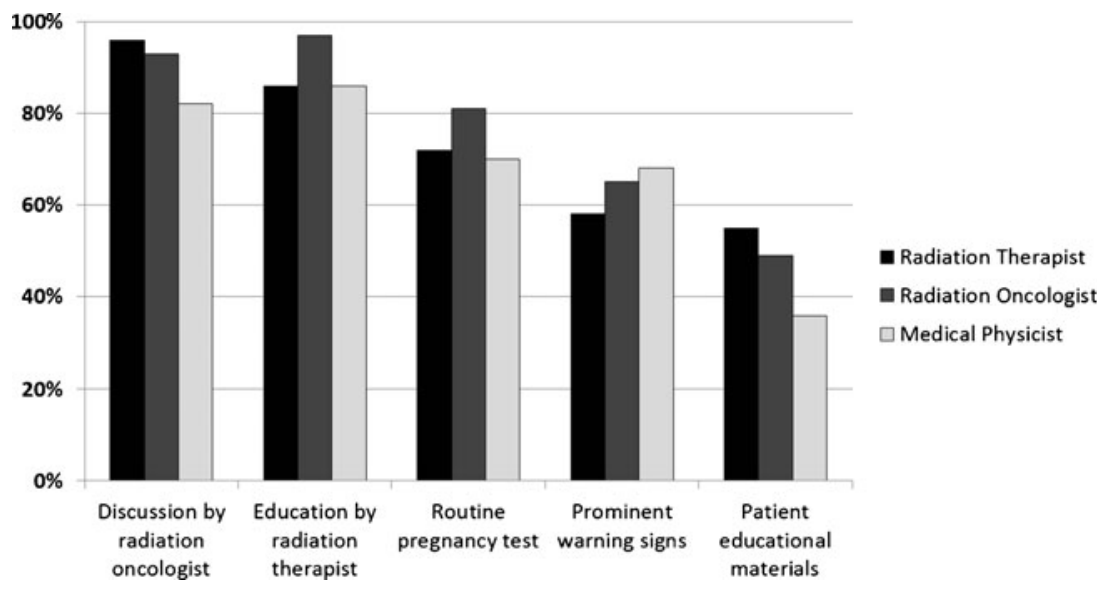

inadvertent treatment of pregnant patients with RT. Of the respondents, $85 \%$ believed that a checklist would be useful that lists the different steps to warn potentially fertile females of the risk of radiation exposure in pregnancy.

\section{Discussion}

This national Canadian survey of radiation oncologists, radiation therapists, and medical physicists demonstrates that these HCPs perceive that there are insufficient mechanisms in place to prevent inadvertent RT of pregnant patients. In addition, 19\% of respondents reported an incident where a pregnant patient was or was almost inadvertently treated with RT. Several potential mechanisms to prevent future incidents were supported by respondents, including the development of national guidelines for RT departments.

This national survey was performed because a survey of BC HCPs suggested they were largely unaware if mechanisms were in place to reduce the risk of inadvertent RT exposure in pregnancy in their province [13]. This national survey demonstrated that the concerns raised in $\mathrm{BC}$ are applicable nationally. In addition, it demonstrates that pregnant patients have received inadvertent RT in the past. The support of national guidelines suggests HCPs require assistance, rather than solely relying on remembering to discuss the risks with their potentially fertile patients.

The results of this survey are timely, given the recent highly publicized radiation errors in international media, with subsequent calls for improvements in safety in radiation oncology departments [14]. To the best of our knowledge, the radiation oncology literature is void of research exploring radiation safety in potentially pregnant women, though limited research has been performed in diagnostic radiology $[15,16]$. Given the concerns raised by HCPs nationally, it is time that North American radiation oncology agencies develop national guidelines to empower local RT departments. Furthermore, research is needed to explore the most effective methods of risk reduction in radiation oncology, including the inadvertent exposure of pregnant patients.

The results of this study should be considered in the context of its strengths and limitations. The results are potentially widely generalizable given it was administered nationally to the three occupations most central to the functioning of a RT department. However, the relatively lowresponse rate suggests the results may be prone to response bias, where respondents with certain characteristics (such as experience with inadvertent RT) may be more likely to return surveys and thereby result in higher proportion of reported experience with inadvertent RT in pregnancy than exists in the true population [17]. Furthermore, the high rates of support for future interventions may be a result of selection bias. Our survey also does not capture the actual number of cases in which pregnant patients are inadvertently irradiated. Therefore, the frequency of this event is not known, but is likely very low. However, the identification that RT departments across Canada have experience with inadvertent RT to pregnant patients is alarming no matter how low the actual rate is. Although the nature of study design does not allow for investigation of the actual effectiveness of proposed interventions, it can serve as a starting point for future research and potential national guideline development.

\section{Conclusion}

Almost one fifth of surveyed Canadian HCPs involved in the delivery of RT have experienced an event in which a pregnant patient received or almost received inadvertent RT. In addition, they perceive that there are inadequate mechanisms in place to prevent the inadvertent administration of RT to pregnant patients. Several mechanisms to prevent future inadvertent RT to pregnant women was supported by respondents, 
including the development of national guidelines and completion of safety checklists. This research also raises the possibility that other countries, such as the USA, should investigate the mechanisms in place to protect women from inadvertent RT to pregnant patients.

Acknowledgments These results were presented at the Canadian Association of Radiation Oncology 2011 Annual Meeting, in Winnipeg, MB, Canada on September 14-17, 2011.

Conflict of interest The authors declare they have no conflict of interest

\section{References}

1. Kal HB, Struikmans H (2005) Radiotherapy during pregnancy: fact and fiction. Lancet Oncol 6:328-333. doi:10.1016/S14702045(05)70169-8

2. Pavlidis NA (2002) Coexistence of pregnancy and malignancy. Oncologist 7:279-287

3. Nieminen U, Remes N (1970) Malignancy during pregnancy. Acta Obstet Gynecol Scand 49:315-319. doi:10.3109/00016347009157259

4. Donegan WL (1983) Cancer and pregnancy. CA Cancer J Clin 33:194-214

5. Antonelli NM, Dotters DJ, Katz VL, Kuller JA (1996) Cancer in pregnancy: a review of the literature. Part I. Obstet Gynecol Surv $51: 125-134$

6. Bradley B, Fleck A, Osei EK (2006) Normalized data for the estimation of fetal radiation dose from radiotherapy of the breast. Br J Radiol 79:818-827. doi:10.1259/bjr/16416346
7. Nakagawa K, Aoki Y, Kusama T, Ban N, Nakagawa S, Sasaki Y (1997) Radiotherapy during pregnancy: effects on fetuses and neonates. Clin Ther 19:770-777. doi:10.1016/S0149-2918(97)80101-4

8. Jankowski CB (1986) Radiation and pregnancy. Putting the risks in proportion. Am J Nurs 86:260-265

9. Miller RW (1969) Delayed radiation effects in atomic-bomb survivors. Major observations by the Atomic Bomb Casualty Commission are evaluated. Science 166:569-574

10. Doll R, Wakeford R (1997) Risk of childhood cancer from fetal irradiation. Br J Radiol 70:130-139

11. de Wildt SN, Taguchi N, Koren G (2009) Unintended pregnancy during radiotherapy for cancer. Nat Clin Pract Oncol 6:175-178. doi: $10.1038 /$ ncponc 1320

12. Stovall M, Blackwell CR, Cundiff J, Novack DH, Palta JR, Wagner LK, Webster EW, Shalek RJ (1995) Fetal dose from radiotherapy with photon beams: report of AAPM Radiation Therapy Committee Task Group No. 36. Med Phys 22:63-82

13. Caon J, Olson R, Tyldesley S, Bergman A, Bobinski MA, Fong M, Ma V, Vellani R, Goddard K (2011) Assessing the risk of inadvertent radiation exposure of pregnant patients during radiation therapy planning and treatment in British Columbia. Prac Radiat Oncol. doi:10.1016/j.prro.2011.08.007

14. Hendee W, Herman M (2011) Improving patient safety in radiation oncology. Med Phys 38:78-82

15. Devine CE, Mawlawi O (2010) Radiation safety with positron emission tomography and computed tomography. Semin Ultrasound CT MR 31:39-45. doi:10.1053/j.sult.2009.09.005

16. Best PJ, Skelding KA, Mehran R, Chieffo A, Kunadian V, Madan M, Mikhail GW, Mauri F, Takahashi S, Honye J, Hernandez-Antolin R, Weiner BH, Society for Cardiovascular Angiography \& Interventions' Women in Innovations (WIN) Group (2011) SCAI consensus document on occupational radiation exposure to the pregnant cardiologist and technical personnel. EuroIntervention 6:866-874. doi:10.4244/EIJV6I7A148;10.4244/EIJV6I7A148

17. Sheikh K, Mattingly S (1981) Investigating non-response bias in mail surveys. J Epidemiol Community Health 35:293-296 